\title{
Penggunaan Pasir dan Serat Kayu Aren sebagai Media Tanam Terong dan Tomat dengan Sistem Hidroponik
}

\section{Use of Sand and Arenga Wood Fiber as Eggplant and Tomato Planting Media with Hidroponik System}

\author{
Handiyan Kharisma Putra ${ }^{1)}$, Dwi Harjoko ${ }^{2)}$, Hery Widijanto ${ }^{2)}$
}

\section{ABSTRACT}

Sands have large pores so can dry quickly by evaporation process. One attempt to do to improve the productivity of sands by increasing the water holding capability with addition of organic fibers. One of them is a waste of arenga wood fiber that has not been handled properly. The purpose of this research is to determine the composition of the sand media combinations of arenga wood fiber which most suitable for planting of eggplant and tomato. This research was carried out in June to September 2013 in the screenhouse of Badan Penyuluhan Pertanian Perikanan dan Kehutanan (BP3K) Cangkringan Sleman regency. This study used a Completely Randomized Design (CRD) using a single factor which 7 treatments tested on eggplant and tomato, each treatment was repeated 5 times. Experimental data were analyzed using analysis of variance and DMRT at $5 \%$ level. The results showed that the treatment of planting media only affects to eggplant leaf number and weight of fruit per plant on both commodities. The highest number of leaves produced by the use of charcoal husk is 25.2 strands. The highest eggplant fruit weight per plant produced by the use of the washed sand medium was $209.36 \mathrm{~g}$ and $352.72 \mathrm{~g}$ for tomato planted on doesn't wash sand.

Keywords : hydroponic, eggplant, tomato, sand, arenga wood fiber

\section{PENDAHULUAN}

Hidroponik dapat dijadikan solusi yang tepat untuk mengatasi permasalahan produksi tanaman terutama di lahan terbuka (open field). Penggunaan sistem hidroponik tidak mengenal musim dan tidak memerlukan lahan yang luas dibandingkan dengan kultur tanah untuk menghasilkan satuan produktivitas yang sama (Lonardy 2006). Pasir sering digunakan sebagai media tanam alternatif untuk menggantikan fungsi tanah. Namun pasir memiliki pori-pori berukuran besar (pori-pori makro), substitusi atau penambahan bahan organik yang bersifat menahan air dapat memperbaiki sifat pasir tersebut. Menurut Supriyanto et al. (1986), media tanam yang baik harus mempunyai sifat fisik yang baik, dan kelembaban harus tetap dijaga serta saluran drainasenya juga harus baik. Banyak penelitian yang mengindikasikan keuntungan dari pencampuran media tanam organik dan anorganik untuk sayuran dengan peningkatan kinerja dalam produksi rumah kaca (Tzortzakis dan Economakis 2008). Komponen organik terurai selama produksi tanaman dan dapat berubah baik secara fisik maupun kimia (Bilderback 2005).

Serat organik yang digunakan pada penelitian ini adalah limbah serat kayu aren yang belum tertangani dengan baik. Oleh karena itu perlu dilakukan studi untuk mengetahui potensi limbah serat kayu aren khususnya dalam industri pertanian. Penelitian ini mencoba untuk mengetahui komposisi media tanam

\footnotetext{
1) Undergraduate Student of Study Program of Agrotechnology, Faculty of Agriculture, University of Sebelas Maret (UNS) in Surakarta.

2) Lecturer of Study Program of Agrotechnology, Faculty of Agriculture, University of Sebelas Maret (UNS) in Surakarta.
}

Contact Author: dwi.harjoko.31@facebook.com dari kombinasi pasir dan serat kayu aren yang paling sesuai sebagai media tumbuh tanaman terong dan tomat. Dengan melakukan studi budidaya terong dan tomat dengan sistem hidroponik pada media pasir Merapi dan serat kayu aren diharapkan dapat memberikan manfaat bagi masyarakat khususnya petani dan pelaku industri tepung aren yang hingga saat ini sedang menghadapi kendala dalam pengelolaan limbah.

\section{METODE PENELITIAN}

Penelitian ini dilaksanakan pada bulan Juni sampai September 2013 di Screenhouse Badan Penyuluhan Pertanian Perikanan dan Kehutanan (BP3K) Kecamatan Cangkringan Kabupaten Sleman. Bahan tanaman yang digunakan dalam penelitian ini adalah benih tanaman terong Varietas Pandega dan tomat Varietas Intan. Bahan lain yang digunakan yaitu pasir Merapi, serat kayu aren, dan nutrisi hidroponik A-B mix. Peralatan yang digunakan meliputi alat-alat untuk mempersiapkan media tanam, pemeliharaan, dan pengamatan, yaitu cangkul, cethok, saringan pasir, polybag, ajir, sprayer, penggaris, timbangan, oven, dan kamera digital. Penelitian ini menggunakan Rancangan Acak Lengkap (RAL) dengan menggunakan faktor perlakuan tunggal yaitu media tanam. Adapun faktor media tanam tersebut memiliki 7 taraf antara lain $\mathrm{M0}=$ Arang sekam (Kontrol) $\mathrm{M} 1=$ Pasir tidak cuci $; M 2=$ Pasir cuci $; M 3=$ Pasir tidak cuci dan serat kayu aren rendam air ; M4 = Pasir cuci dan serat kayu aren rendam air ; M5 = Pasir tidak cuci dan serat kayu aren rendam fungisida ; M6 = Pasir cuci dan serat kayu aren rendam fungisida. Tujuh jenis media tanam (M0-M6) kemudian diujikan pada 2 tanaman yaitu terong dan tomat, dan masing-masing perlakuan diulang 5 kali. Pengamatan yang dilakukan meliputi tinggi tanaman, jumlah daun, berat kering 
tajuk, berat kering akar, jumlah buah per tanaman, berat buah per tanaman, dan berat buah per butir. Khusus untuk tanaman tomat dilakukan pengamatan komponen kualitas yaitu kadar vitamin c dan kadar gula. Data hasil percobaan dianalisis menggunakan analisis ragam (Anova) pada taraf 5\%. Jika analisis ragam berbeda nyata atau sangat nyata, maka dilanjutkan dengan Duncan's Multiple Range Test (DMRT) pada taraf 5\% (Gasperz 1991).

\section{HASIL DAN PEMBAHASAN}

\section{Komponen Pertumbuhan}

Penggunaan pasir cuci memberikan hasil tertinggi terhadap tinggi tanaman terong (Gambar 1) yaitu sebesar $95,82 \mathrm{~cm}$. Demikian pula pada rerata tinggi tanaman tomat dengan nilai tertinggi yaitu $170,9 \mathrm{~cm}$ (Gambar 2 ). Hal ini menunjukkan bahwa penggunaan media pasir tanpa penambahan serat kayu aren memiliki rerata tinggi tanaman tertinggi pada tanaman terong maupun tomat. Harjadi (1988) menyatakan media tanam yang digunakan merupakan tempat menyimpan dan melayani air serta nutrisi.

Tabel 1 menunjukkan bahwa semua perlakuan memberikan hasil yang cukup baik terhadap variabel jumlah daun terong. Penggunaan media tanam arang sekam yang merupakan perlakuan kontrol menghasilkan rerata jumlah daun tertinggi yaitu 25,2 helai daun.

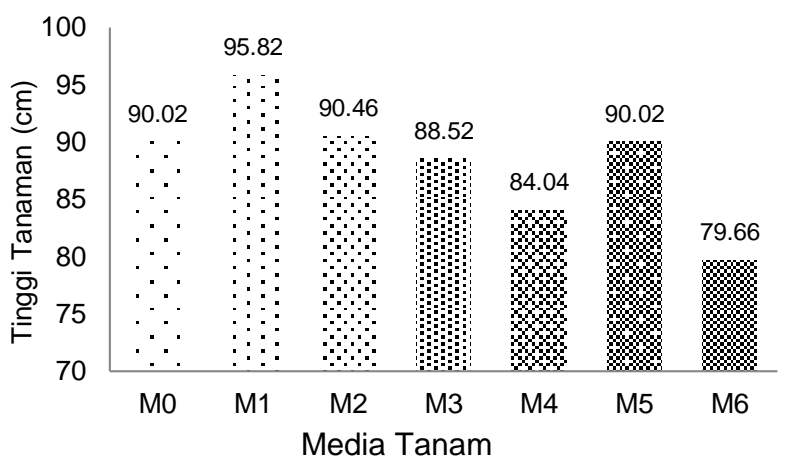

Gambar 1. Pengaruh media tanam pasir Merapi dan serat kayu aren terhadap tinggi tanaman terong pada $13 \mathrm{MST}$

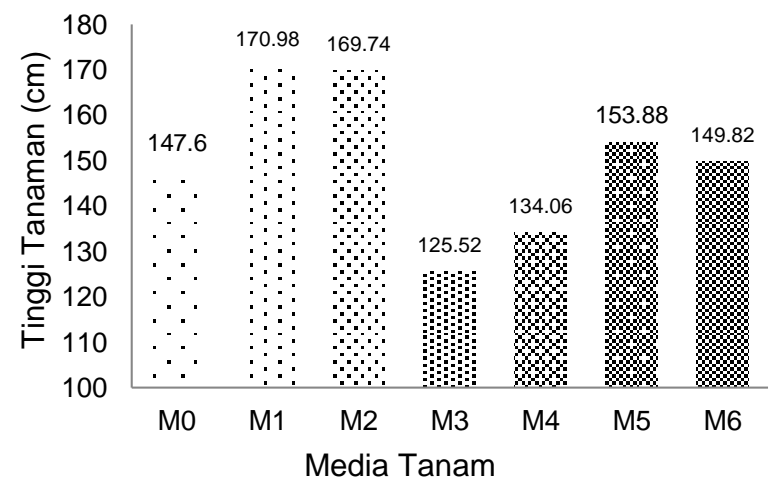

Gambar 2. Pengaruh media tanam pasir Merapi dan serat kayu aren terhadap tinggi tanaman tomat pada $13 \mathrm{MST}$
Tabel 1. Pengaruh media pasir Merapi dan serat kayu aren terhadap jumlah daun tanaman terong pada 13 MST

\begin{tabular}{ccc}
\hline Media tanam & Jumlah daun & Nilai Relatif $(\%)$ \\
\hline M0 & $25,2^{\mathrm{c}}$ & 100,00 \\
M1 & $21,8^{\mathrm{b}}$ & 86,51 \\
M2 & $20,0^{\mathrm{ab}}$ & 79,37 \\
M3 & $20,2^{\mathrm{ab}}$ & 80,16 \\
M4 & $19,0^{\mathrm{a}}$ & 75,4 \\
M5 & $19,8^{\mathrm{ab}}$ & 78,57 \\
M6 & $18,6^{\mathrm{a}}$ & 73,81 \\
\hline
\end{tabular}

Keterangan: Nilai yang diikuti huruf berbeda menunjukkan berbeda nyata pada DMRT taraf $5 \%$.

Karakteristik arang sekam yang baik dapat menunjang pembentukan tanaman, yaitu ringan (berat jenis $0,2 \mathrm{~kg} \mathrm{l}^{-1}$ ), sirkulasi udara tinggi, kapasitas menahan air tinggi, berwarna kehitaman, sehingga dapat mengabsorbsi sinar matahari dengan efektif (Wuryaningsih 1996).

Sedangkan jumlah daun tanaman tomat (Gambar 3) terbanyak dihasilkan pada penggunaan media tanam pasir tidak cuci tanpa penambahan serat kayu aren yaitu 31,8 helai.

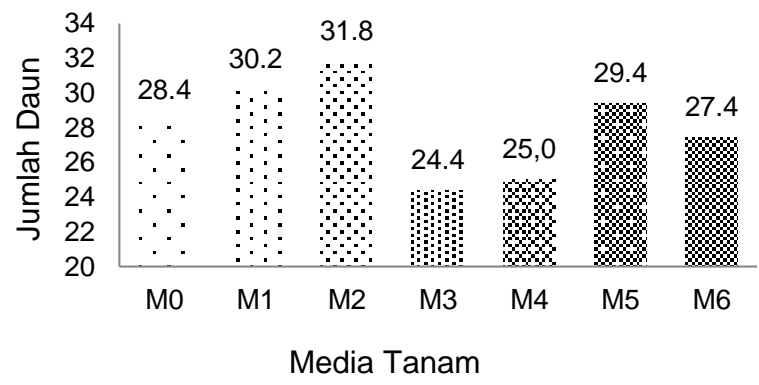

Gambar 3. Pengaruh media tanam pasir Merapi dan serat kayu aren terhadap jumlah daun tanaman tomat pada $13 \mathrm{MST}$

Kedua kombinasi media tanam pasir dan serat kayu aren rendam air memiliki rerata berat kering tajuk tertinggi pada tanaman terong (Gambar 4), baik itu dengan penggunaan pasir cuci yang mencapai 30,04 gram maupun pasir tidak cuci yang mencapai 29,27 gram. Secara mandiri penggunaan tambahan serat kayu aren rendam air dapat lebih menunjang nilai berat kering tajuk tanaman terong.

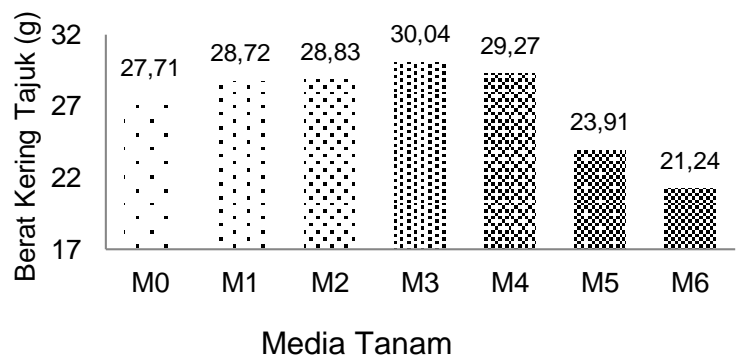

Gambar 4. Pengaruh media tanam pasir Merapi dan serat kayu aren terhadap berat kering tajuk tanaman terong 
Sedangkan untuk tanaman tomat (Gambar 5), penggunaan media tanam pasir tanpa penambahan serat kayu aren memiliki nilai rerata yang tertinggi. Yaitu 35,518 gram untuk pasir tidak cuci dan 35,518 gram untuk pasir cuci. Nilai berat kering tajuk terendah ditunjukkan pada penggunaan media tanam pasir tidak cuci dan serat kayu aren rendam fungisida (M6) yang hampir setara dengan penggunaan media tanam arang sekam (M0).

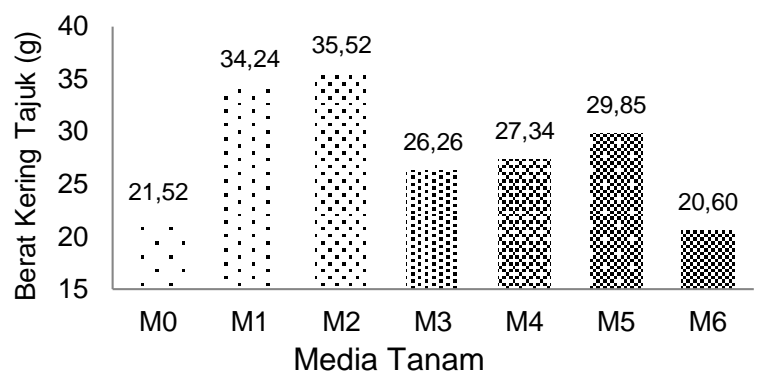

Gambar 5. Pengaruh media tanam pasir Merapi dan serat kayu aren terhadap berat kering tajuk tanaman tomat.

Penggunaan pasir tanpa penambahan serat kayu aren menunjukkan berat kering akar tertinggi (Gambar 6 dan 7) dibandingkan perlakuan lainnya pada kedua tanaman (terong dan tomat). Hal ini diduga karena media pasir merupakan media yang sangat porous, mudah meloloskan larutan nutrisi, aerasi dan drainasenya baik sehingga memudahkan pertumbuhan dan perkembangan akar. Sifat fisik serat kayu aren yang keras sulit untuk ditembus akar tanaman karena mengandung lignin. Menurut Barlianti dan Wiloso (2008) Kandungan lignin yang tinggi pada suatu media organik dapat mengurangi percepatan pembusukan. Manipulasi media tumbuh yang tepat adalah dengan membuat komposisi media yang dapat mempertahankan kelembaban tanah dalam waktu relatif lebih lama dan mampu menyediakan unsur hara bagi tanaman (Muliawati 2001). Namun demikian, penambahan serat kayu aren yang bertujuan membantu kemampuan media pasir dalam menjerap air tidak mampu menghasilkan biomassa akar yang lebih tinggi dari media pasir saja. Beberapa penelitian telah menyebutkan bahwa sabut kelapa yang merupakan bahan organik mempunyai daya simpan air yang sangat baik (Muhit dan Qodriyah 2006).

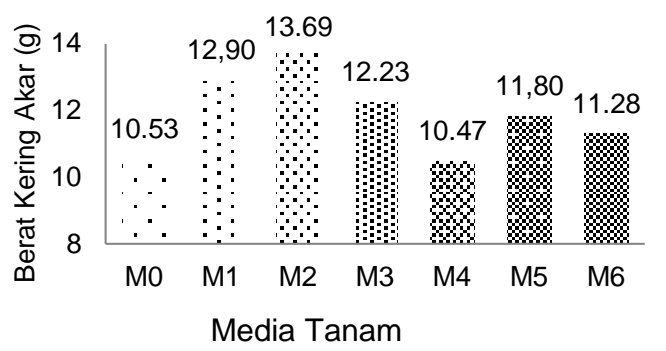

Gambar 6. Pengaruh media tanam pasir Merapi dan serat kayu aren terhadap berat kering akar tanaman terong

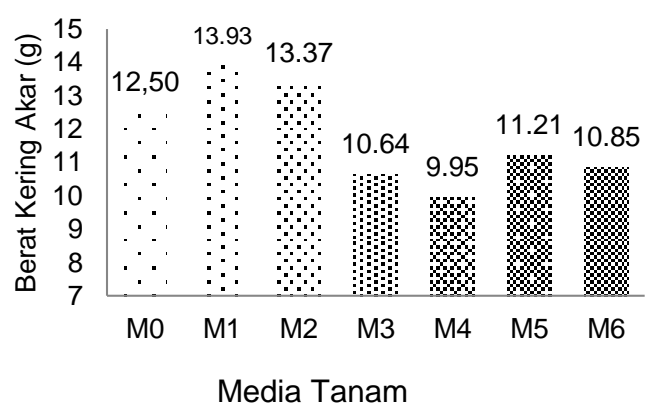

Gambar 7. Pengaruh media tanam pasir Merapi dan serat kayu aren terhadap berat kering akar tanaman tomat

Pertumbuhan akar yang terhambat pada tingkat kepadatan media yang dapat dilihat dari berat keringnya. Semakin tinggi tingkat kepadatan media maka semakin rendah berat keringnya. Islami dan Utomo (1995) menyatakan bahwa peningkatan panjang dan volume akar tidak selalu berpengaruh positif terhadap pertumbuhan dan hasil tanaman. Sistem akar yang kecil dapat mendukung hasil yang tinggi asalkan zat-zat hara tersedia dengan baik (Goldsworty dan Fisher 1984).

\section{Komponen Hasil}

Penggunaan pasir tidak cuci tanpa penambahan serat kayu aren juga memberikan hasil tertinggi untuk tanaman tomat (Gambar 9) yang mencapai rerata 7,8 buah per tanaman.

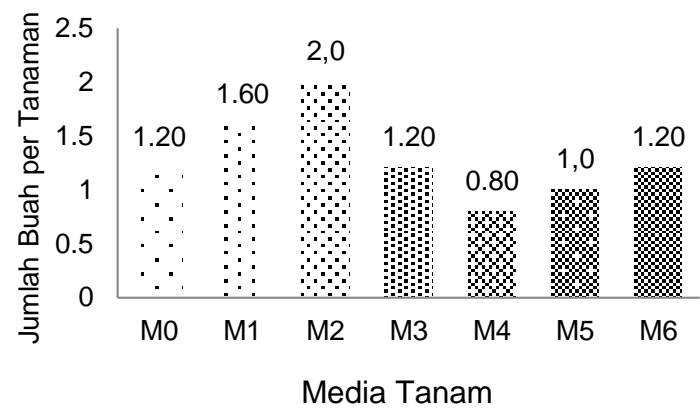

Gambar 8. Pengaruh media tanam pasir Merapi dan serat kayu aren terhadap jumlah buah per tanaman terong

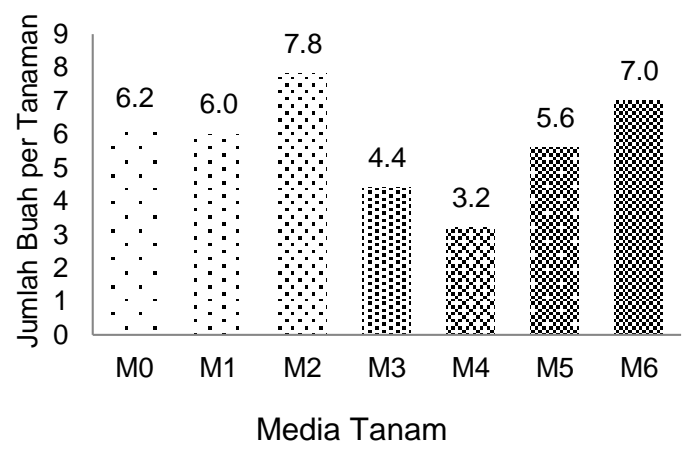

Gambar 9. Pengaruh media tanam pasir Merapi dan serat kayu aren terhadap jumlah buah per tanaman tomat 
Berdasarkan Tabel 2 pada variabel berat buah per tanaman terong, dengan penggunaan media pasir

cuci tanpa penambahan serat kayu aren menunjukkan hasil tertinggi yaitu 209,36 gram.

Tabel 2. Pengaruh media pasir Merapi dan serat kayu aren terhadap berat buah per tanaman terong dan tomat

\begin{tabular}{ccccc}
\hline $\begin{array}{c}\text { Media } \\
\text { tanam }\end{array}$ & $\begin{array}{c}\text { Berat Buah } \\
\text { terong }(\mathrm{g})\end{array}$ & $\begin{array}{c}\text { Nilai Relatif Berat Buah } \\
\text { Terong }(\%)\end{array}$ & $\begin{array}{c}\text { Berat Buah tomat } \\
(\mathrm{g})\end{array}$ & $\begin{array}{c}\text { Nilai Relatif Berat Buah } \\
\text { Tomat }(\%)\end{array}$ \\
\hline M0 & $136,51^{\mathrm{ab}}$ & 100 & $166,46^{\mathrm{abc}}$ & 100,00 \\
M1 & $209,36^{\mathrm{b}}$ & 153,37 & $314,63^{\mathrm{bc}}$ & 189,01 \\
M2 & $153,95^{\mathrm{ab}}$ & 112.78 & $352,72^{\mathrm{c}}$ & 211,89 \\
M3 & $64,43^{\mathrm{a}}$ & 47.2 & $126,42^{\mathrm{ab}}$ & 75,95 \\
M4 & $51,12^{\mathrm{a}}$ & 37.45 & $102,35^{\mathrm{a}}$ & 61,49 \\
M5 & $71,48^{\mathrm{a}}$ & 52.36 & $244,01^{\mathrm{abc}}$ & 146,59 \\
M6 & $125,97^{\mathrm{ab}}$ & 92.28 & $286,16^{\mathrm{abc}}$ & 171,91 \\
\hline
\end{tabular}

Keterangan: Nilai yang diikuti huruf berbeda pada kolom yang sama menunjukkan berbeda nyata pada DMRT taraf $5 \%$.

Berat buah per tanaman tomat pada penggunaan media tanam pasir tanpa menggunakan tambahan serat kayu aren (M1 dan M2) berbeda nyata dengan penggunaan media tanam pasir dengan tambahan serat kayu aren (M3, M4, M5, dan M6). Penambahan serat aren pada media tanam pasir cenderung menghasilkan berat buah per tanaman yang lebih rendah daripada penggunaan media tanam pasir saja.

Gambar 10 dan 11 menjelaskan bahwa penggunaan media tanam pasir tanpa penambahan serat kayu aren yang menghasilkan berat per buah tertinggi pada kedua komoditas. Hal ini menunjukkan bahwa media pasir saja memiliki kemampuan menyediakan air bagi tanaman yang lebih baik daripada media campuran serat kayu aren dan pasir. Saat vegetatif maupun generatif, tanaman membutuhkan air dalam jumlah besar karena air merupakan komponen penting yang dibutuhkan tanaman baik dalam pertumbuhan, transport maupun menunjang dalam pembentukan buah (Lestari 2003).

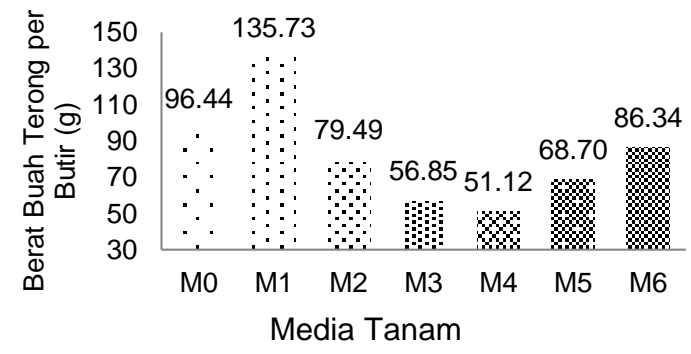

Gambar 10. Pengaruh media tanam pasir Merapi dan serat kayu aren terhadap berat buah terong per butir

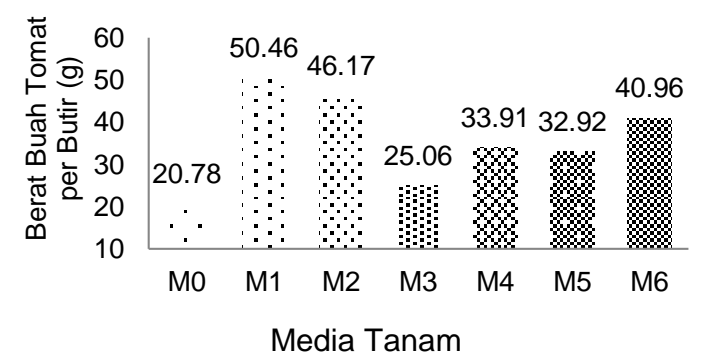

Gambar 11. Pengaruh media tanam pasir Merapi dan serat kayu aren terhadap berat buah tomat per butir

\section{Komponen Kualitas}

Penggunaan media tanam pasir tidak cuci dengan penambahan serat kayu aren rendam air memiliki rerata kadar vitamin $\mathrm{C}$ tertinggi yaitu $1,94 \mathrm{mg} \mathrm{ml}^{-1}$. Sementara penggunaan media tanam pasir cuci tanpa penambahan serat kayu aren memiliki rerata kadar vitamin $C$ terendah yaitu $1,47 \mathrm{mg} \mathrm{ml}^{-1}$.

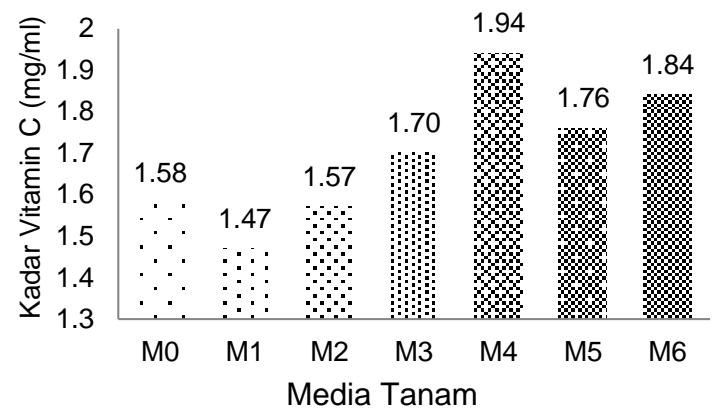

Gambar 12. Pengaruh media tanam pasir Merapi dan serat kayu aren terhadap kadar vitamin C buah tomat

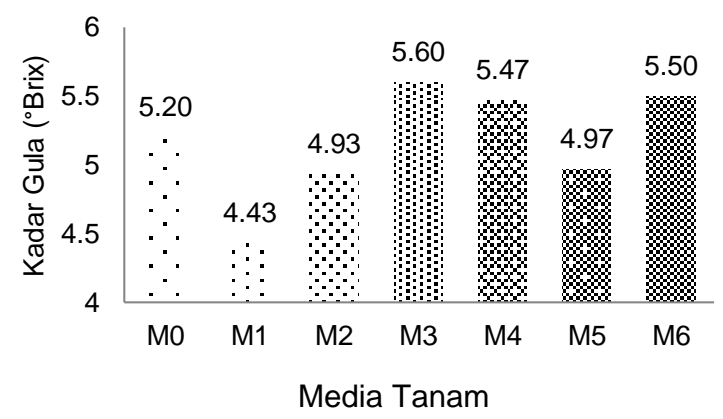

Gambar 13 Pengaruh media tanam pasir Merapi dan serat kayu aren terhadap kadar gula buah tomat.

Kondisi cekaman air pada tanaman menghasilkan gula lebih banyak bila dibandingkan dengan tanaman yang tidak dalam kondisi tercekam. Hal ini sejalan dengan pendapat Esya (1997) melaporkan bahwa kondisi cekaman air $60 \%$ dari kapasitas lapang, kadar buah total buah melon meningkat bila dibandingkan dengan keadaan tanaman cukup air, namun bobot buah menurun seiring dengan menurunnya kadar air tanah. Diduga penambahan serat kayu aren pada media pasir menghambat penyerapan nutrisi oleh 
akar tanaman tomat sehingga mempengaruhi semua peubah yang diamati. Sehubungan dengan hasil penelitian Azis et al. (2006), bahwa penyerapan nutrisi yang cukup pada tanaman akan mempercepat laju pembelahan dan pemanjangan sel, pertumbuhan akar, batang, dan daun berlangsung dengan cepat.

\section{KESIMPULAN DAN SARAN}

\section{Kesimpulan}

Hasil penelitian menunjukkan bahwa jenis media tanam hanya mempengaruhi jumlah daun tanaman terong dan berat buah per tanaman pada kedua komoditas. Penggunaan media arang sekam menghasilkan rerata jumlah daun terong tertinggi yaitu 25,2 helai. Sedangkan jumlah daun terong minimal ditunjukkan oleh penggunaan media tanam pasir tidak cuci dan serat kayu aren rendam fungisida yaitu 18,6 helai. Rerata berat buah per tanaman tertinggi pada kedua komoditas dihasilkan dari penggunaan media pasir tanpa serat aren, yaitu 209,36 g buah terong pada pasir cuci, dan 352,72 g buah tomat pada pasir tidak cuci. Penggunaan pasir tanpa penambahan serat kayu aren baik itu pasir cuci dan tidak cuci menunjukkan kecenderungan hasil paling baik untuk pertumbuhan dan hasil tanaman terong. Penggunaan pasir tanpa penambahan serat kayu aren baik itu pasir cuci dan tidak cuci menunjukkan kecenderungan hasil paling baik untuk pertumbuhan dan hasil tanaman tomat.

\section{Saran}

Penelitian selanjutnya akan lebih baik jika menggunakan faktor perbandingan komposisi jumlah media pasir dan serat kayu aren untuk mengetahui potensi serat kayu aren pada jumlah tertentu.

\section{PERSANTUNAN}

Penulis mengucapkan terima kasih kepada Ir. Dwi Harjoko, M.P. dan BOPTN UNS atas pendanaannya selama proses penelitian serta Kepala dan Staff Badan Penyuluhan Pertanian Perikanan dan Kehutanan (BP3K) Kabupaten Sleman atas perijinan penggunaan screenhouse sebagai tempat penelitian.

\section{DAFTAR PUSTAKA}

Azis AH, Surung MY, Buraerah. 2006. Produktivitas tanaman selada pada berbagai dosis posidan-HT. J Agric 2: 36-42.

Barlianti V, El-Wiloso. 2008. Potensi pemanfaatan lingo selulosa pada coir dust sebagai penyerap tumpahan minyak pada air. Berita Selulosa 43: 101-106.

Bilderback T. 2005. Substrates need physicals. Hort Tech 15: 747-751.

Esya LV. 1997. Pengaruh konsentrasi cycocel (ccc) terhadap pertumbuhan dan hasil tanaman melon pada kondisi kekeringan. Skripsi. Padang (ID): Universitas Andalas. 68 hal.

Harjadi S. 1988. Pengantar agronomi. Jakarta (ID): Gramedia.
Islami T, Utomo WH. 1995. Hubungan tanah air dan tanaman. Semarang (ID): IKIP Semarang Press.

Lestari E. 2003. Simulasi potensi hasil dan pengaruh cekaman air pada tanaman kentang (Solanum tuberosum I.) di kecamatan lembang kabupaten bandung. Skripsi. Institut Pertanian Bogor.

Lonardy MV. 2006. Respons tanaman tomat (Lycopersicon esculentum Mill.) terhadap suplai senyawa nitrogen dari sumber berbeda pada sistem hidroponik. "Skripsi" (Tidak Dipublikasikan). Universitas Tadulako.

Muhit A, Qodriyah L. 2006. Respon beberapa kultivar mawar (Rosa hybrida L.) pada media hidroponik terhadap pertumbuhan dan produksi bunga. Buletin Teknik Pertanian 11: 29-32.

Muliawati ES. 2001. Kajian tingkat serapan hara, pertumbuhan dan produksi sambiloto (Androgaphis paniculata ness.) pada beberapa komposisi media tanam dan tingkat pengairan. Prosiding Simposium Nasional II Tumbuhan Obat dan Aromatik. Bogor (ID): APINMAP.

Supriyanto QD, Erwanto, Setiono. 1986. Pengaruh macam bahan organik media tumbuh terhadap pertumbuhan semai batang bawah jeruk citroen (JC.) Bul Penel Hort (1): 45-48.

Tzortzakis NG, Economakis CD. 2008. Impacts of the substratemedium on tomato yield and fruit quality in soilless cultivation. Horti Sci 35: 83-89.

Wuryaningsih S. 1996. Pertumbuhan beberapa setek melati pada tiga macam media. J Pen Pert 5(3): 50-57. 